\title{
Compressed Air Energy Storage Installation for Renewable Energy Generation
}

\author{
Claudia Borzea $^{1, *}$, Iulian Vlăducă ${ }^{1}$, Dan Ionescu ${ }^{1}$, Valentin Petrescu ${ }^{1}$, Filip Niculescu ${ }^{1}$, \\ Cristian Nechifor ${ }^{1}$, Gabriel Vătășelu ${ }^{2}$, and Mihai Hanek ${ }^{2}$ \\ ${ }^{1}$ Romanian Research and Development Institute for Gas Turbines COMOTI, 061126 Bucharest, \\ Romania \\ ${ }^{2}$ ICPE, Energy Centre, 030138 Bucharest, Romania
}

\begin{abstract}
Compressed Air Energy Storage (CAES) installations are used for storing electrical power, under the form of potential energy from compressed air. The heat generated during compression can be stored to improve the efficiency of compression-expansion cycle. The solution presented consists of a $100 \mathrm{~kW}$ screw compressor driven by a $110 \mathrm{~kW}$ asynchronous three-phase motor. The compressor supplies air into vessels which store it until a high electrical energy demand arises. At that time, the compressed air is released into a $132 \mathrm{~kW}$ screw expander whose shaft spins a $132 \mathrm{~kW}$ asynchronous generator, producing electric power and supplying it into the electrical grid. Before expansion, the air must be preheated in order to avoid the freezing of expansion equipment. If the heat generated during compression is used for air preheating before expansion, the process is adiabatic. A demonstrative model of the installation is currently being developed, with the expander part being completed so far. The maximum power to be produced was calculated to be around $100 \mathrm{~kW}$. During expander commissioning tests with air supply from a $250 \mathrm{~kW}$ high pressure compressor, a maximum generated power of $49.7 \mathrm{~kW}$ was attained, expected to be higher when releasing air from the reservoirs.
\end{abstract}

\section{Overview}

Global concerns on climate changes and sustainability have led to recent worldwide approaches towards generating electricity from renewable sources. The use of renewable energies as a response to the European Union targets defined for 2030 Climate Change and Energy is increasing [1]. Non-dispatchable and intermittent renewable energy sources like wind and solar power cannot meet the necessary supply and demand, which can also cause certain problems in the grid. Some of the major limitations of renewable energy sources are represented by their low power density and intermittence, largely depending upon local site and unpredictable weather conditions.

Compressed air energy storage (CAES) is a technique for supplying electric power to meet peak load requirements of electric utility systems [2], being suitable for wind and solar sources. A CAES power generation facility uses electric motor-driven compressors to

\footnotetext{
* Corresponding author: borzeaclaudia@gmail.com; claudia.borzea@comoti.ro
} 
inject air into a reservoir, later releasing the compressed air to turn turbines and generate electricity back into the grid. High capacity storage media can include underground salt dome caverns, depleted oil/gas reservoirs, underground aquifers, or in certain cases abandoned underground hard rock mines [3]. CAES power plant concept dates back more than 40 years ago $[2,4,5]$, but environmental concerns sustained by technological advances have encouraged their research and development interest to increase worldwide [6-11].

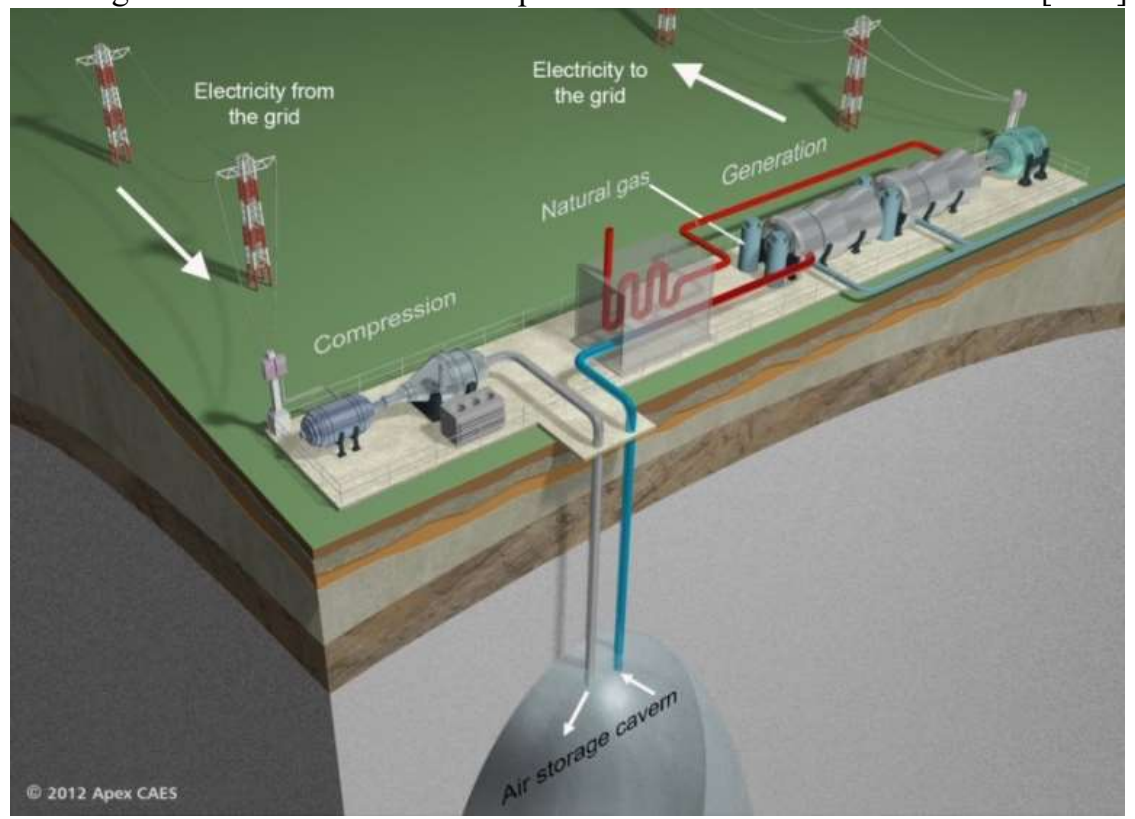

Fig. 1. Design of a CAES power generation facility [3]

In a CAES power generation plant, compression normally occurs during off-peak hours, when power prices are low. During hours of high electricity demand, compressed air is withdrawn from the cavern, preheated, and introduced into one of the several combustors. In the combustors, natural gas is fired to further heat the air, and the hot expanding gases are used to drive expansion turbines. These turbines are connected to a generator, which produces electricity for the grid.

The earliest commercially operated compressed air energy storage system was constructed in Huntorf, Germany, in 1978, with an installed capacity of $290 \mathrm{MW}$. The Huntorf plant is located on a $300,000 \mathrm{~m}^{3}$ salt dome, in which compressed air is stored, originally to capture excess nuclear power production.

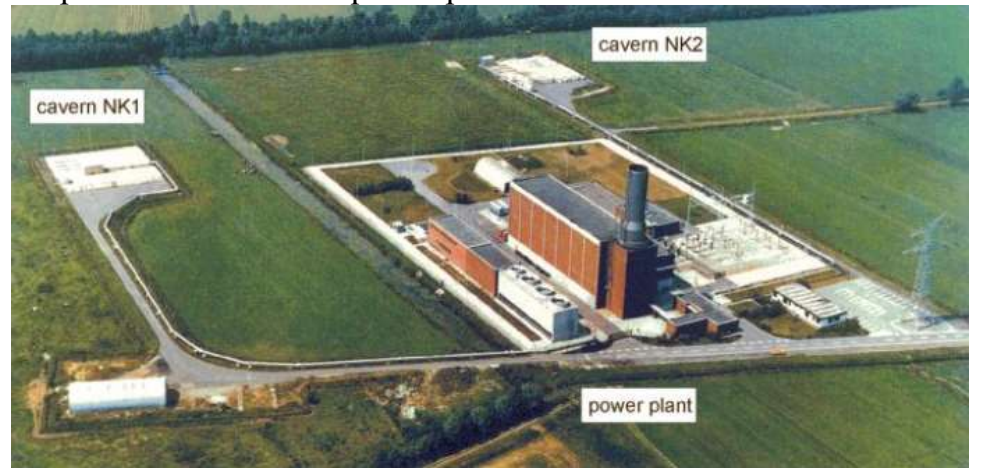

Fig. 2. CAES power plant in Huntorf, Germany [10] 
Another successful CAES system was built in McIntosh, Alabama in USA, in 1991, and can store compressed air in the abandoned salt mines $450 \mathrm{~m}$ underground, providing compressed air to a $110 \mathrm{MW}$ turbine for 26 consecutive hours. The construction of CAES plants is restricted by terrain and has special requirements for the geological structure [11].

Large-scale CAES plants are very inefficient, being commercially viable only in places where electricity price varies dramatically. Compressing and decompressing air introduces energy losses, resulting in an electric-to-electric efficiency of only $40-52 \%$, compared to $70-85 \%$ for pumped hydropower plants, and $70-90 \%$ for chemical batteries [12]. Nevertheless, wind turbines plants relying on the intermittent nature of wind power can make CAES an attractive backup solution. In such systems, energy is stored during periods of low demand and is then converted back into electricity when the demand is high.

The low efficiency is mainly caused by air heating during compression. This waste heat, which holds a large share of the energy input, is dumped into the atmosphere. A related problem is air cooling during decompression, lowering electricity production and possibly freezing water vapours in the air. To avoid this, large-scale CAES plants heat the air prior to expansion using natural gas fuel, which further deteriorates the system's efficiency and makes renewable energy storage dependent on fossil fuels [12].

This paper presents the concept and design of the first Romanian CAES system. A prototype is currently being developed within ROCAES project.

\section{ROCAES installation design and layout}

The design presented is a relatively low scale model, using vessels to store the compressed air and hot water, without gas turbine engines or dynamic compressors (centrifugal or axial) which use fossil fuels. The prototype uses a twin-screw compressor and a twin-screw expander, actuated by three-phased asynchronous electric machines. The block diagram of ROCAES station with integrated SCADA (Supervisory Control and Data Acquisition) automation system is shown in figure 3 below.

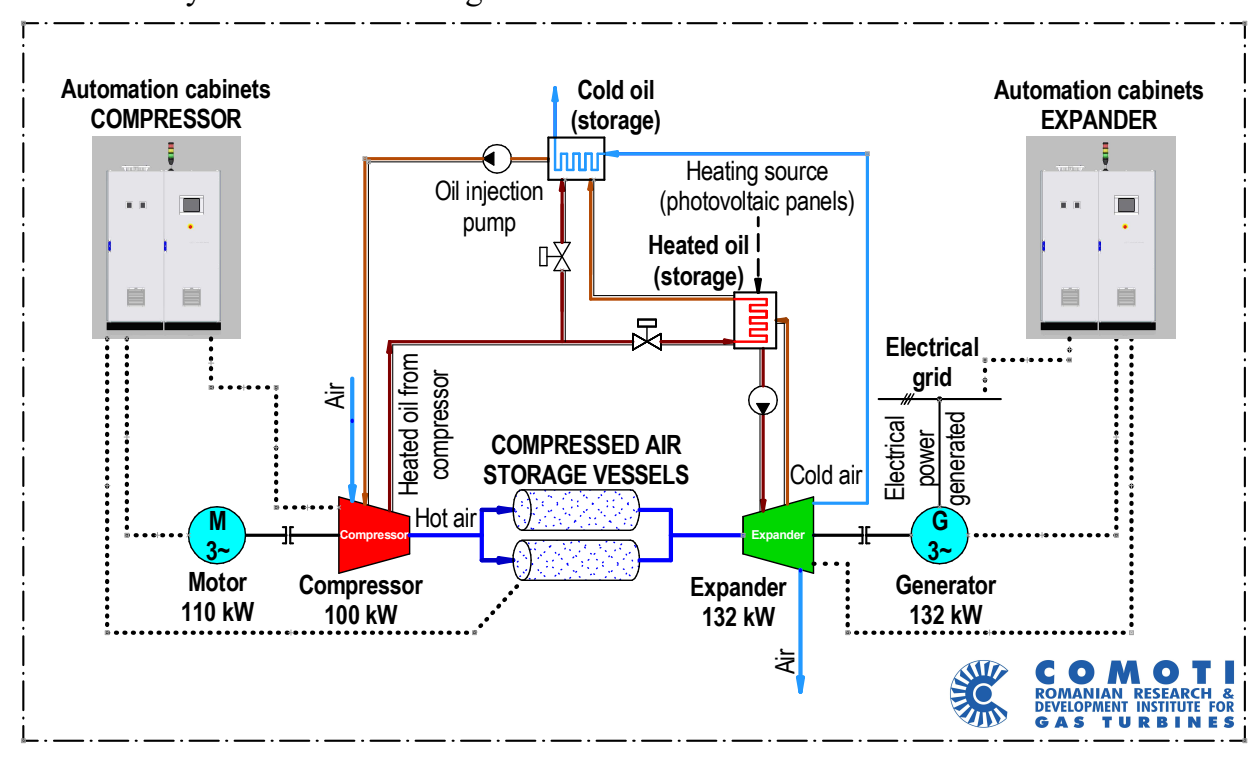

Fig. 3. Block diagram of ROCAES station

The system consists of a $100 \mathrm{~kW}$ twin-screw compressor that supplies compressed air into two storage vessels, and a $132 \mathrm{~kW}$ expander. The compressor is driven by a $110 \mathrm{~kW}$ 
asynchronous three-phase motor. The expander is driven by the compressed air released from the reservoirs, and spins a $132 \mathrm{~kW}$ asynchronous three-phase generator.

The compressor and the expander are not designed for simultaneous operation. The compressor supplies air into the storage tanks in the periods with low cost energy, until the maximum pressure of 26 bar absolute is attained in the vessels. The pressure is permanently monitored by a pressure transducer which transmits information to the PLC (Programmable Logic Controller) in the automation cabinet assigned to compressor and air storage. The compressed air is released from the storage tanks when an increased demand of electrical energy arises. The compressed air turns the expander, whose shaft spins the electrical generator, providing electrical power to the grid.

As presented schematically in figure 4, showing the total scale 1:1 of the 2D view, the overall area of the ROCAES power plant is $285 \mathrm{~m}^{2}$, a relatively small scale CAES facility. The ROCAES plant is a pilot station, and the functional time for demonstration is about half an hour. The overall layout consists of four main areas, as designed, namely:

- Zone 1: Compression skid - $1500 \mathrm{~m}^{3}$ air screw compressor + compressed air storage vessel - $150 \mathrm{~m}^{3}$ at 26 bar absolute air pressure.

- Zone 2: Heating water storage vessel - 1 bar absolute at $90^{\circ} \mathrm{C}$ water storage vessel, with two heat exchangers for oil to water heat transfer.

- Zone 3: Expander skid - $1500 \div 4500 \mathrm{~m}^{3}$ air screw expander.

- Zone 4: Automation and control room - enclosure for automation cabinets, station computer and human operator controls.

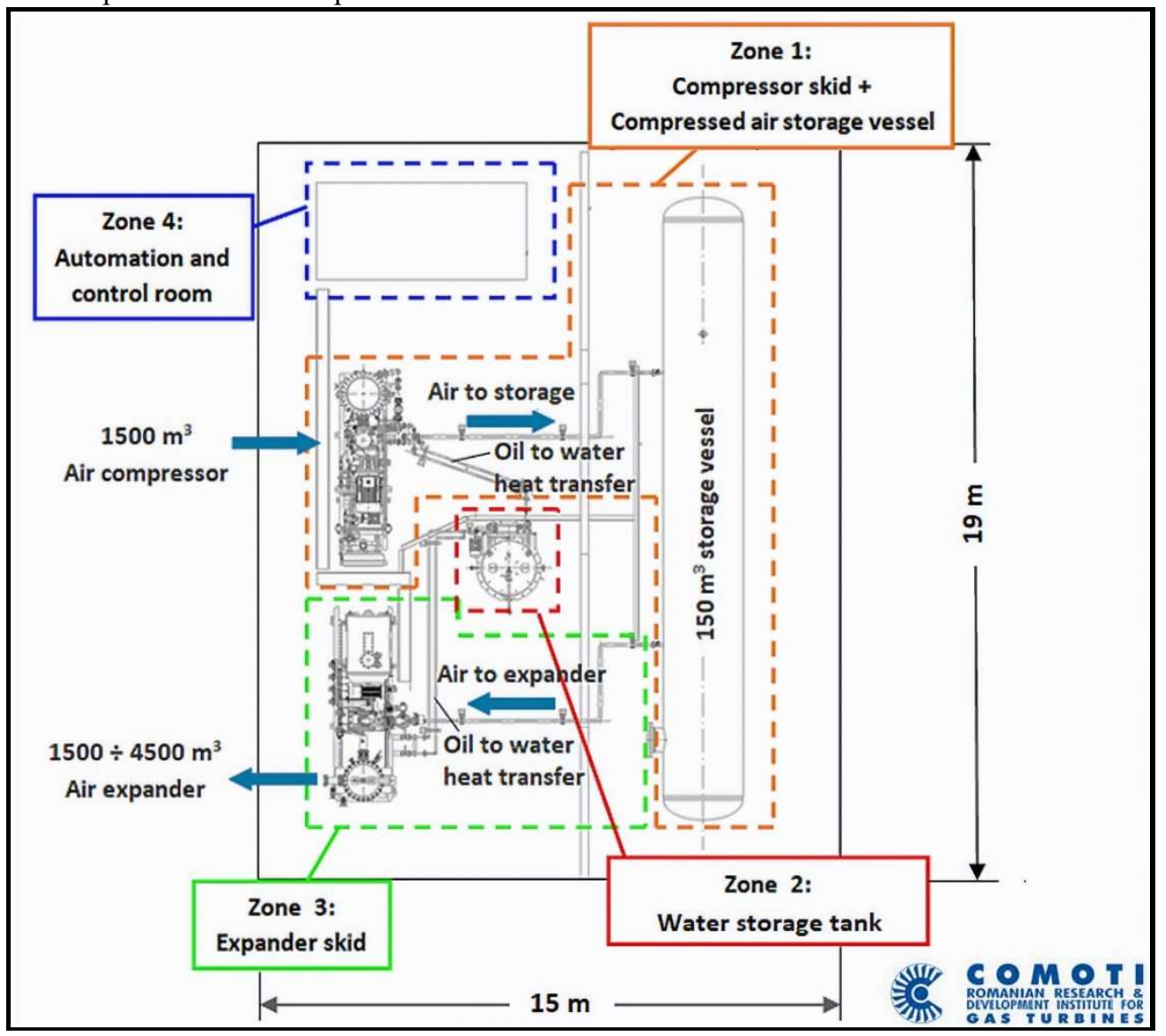

Fig. 4. ROCAES station 2D layout 
During expansion, air temperature can drop below freezing point (down to $-10 \div-15^{\circ} \mathrm{C}$ or even lower). When the compressor is functioning, hot air from compression is accumulated in the storage tanks. The lubrication and cooling oil tray passes through the thermal conditioning unit (water storage tank) and heats the thermal agent transferring heat to the oil circuit of the expander. The oil injection pump of the expander recirculates the oil on the bypass circuit configured by a three-way motor operated valve, ensuring oil heating. After compressor finishes operation, oil recirculation is also stopped for thermal energy conservation in the storage tank, maintaining the lube oil at an optimal temperature.

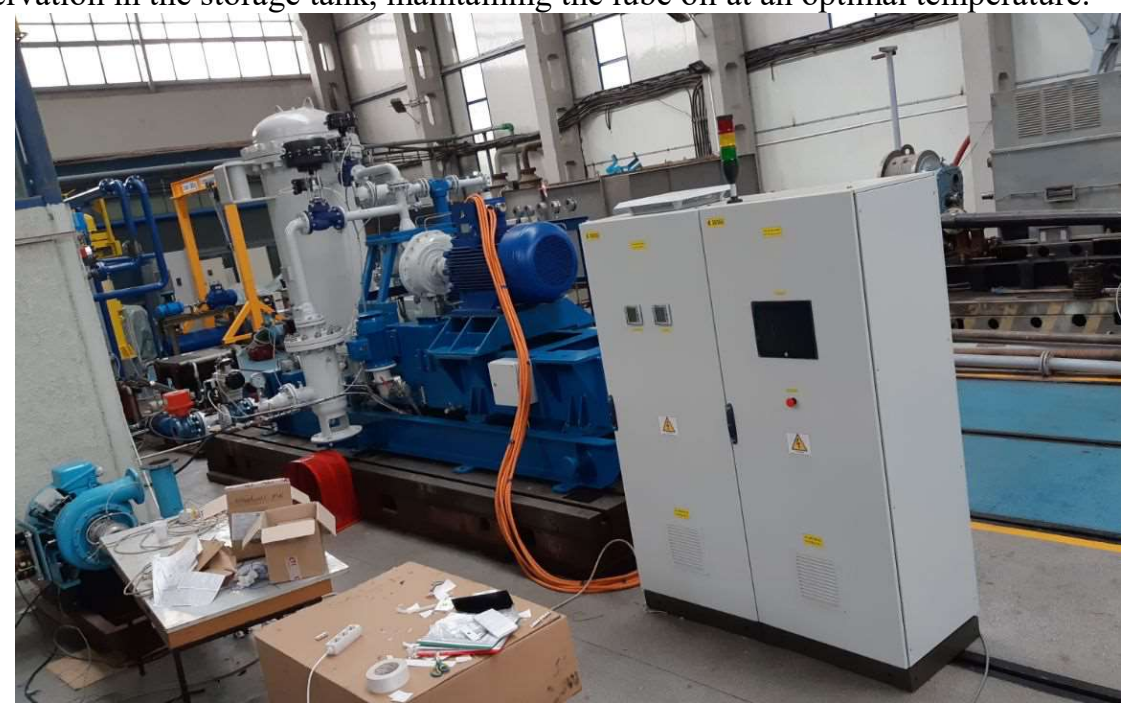

Fig. 5. Expander skid with automation cabinets in the assembly hall

A long period of time, neither the compressor nor the expander will function. The operation of the installation depends on the optimal timing. During idle periods, it is preferable that the compressed air vessels to be full, waiting for air to be released into the expander. If the air inlet motor operated valve is open, a time of approximately $20 \mathrm{~s}$ is estimated until starting to generate electrical energy.

\section{Electrical and automation considerations}

The purpose of the automated SCADA system represented by the drives and automation cabinets is to monitor the operation parameters of thermal, mechanical and electrical processes, to regulate and keep these ones under control, in order to ensure maximum safety conditions.

On compressor and expander skids, transducers are mounted for monitoring the important parameters of the installation. Local indication is realized by means of manometers and thermometers. For the important sizes that need to be transmitted to PLC for a safe operation, pressure transducers are mounted in several points for monitoring air and lube oil pressures. The air flow before inlet is monitored by means of differential pressure cells with orifice plate, which constitute analogue inputs into PLC. Temperature data is acquired using PT100 resistance temperature detectors (RTD) for air temperature on inlets and lube oil temperature in the storage tank. The information from the transducers is transmitted to two PLCs, so as the expander and the compressor to be able to operate independently of one another. The analogue I/O (inputs/outputs) signals for varying parameters are transmitted in unified current signal 4-20 mA. The digital I/O (open/close, on/off type) are transmitted in $0-24 \mathrm{VDC}$ voltage signal. 
On expander skid, the automation system controls two motor operated valves for air inlet and oil bypass, a solenoid valve with rapid response for emergency shutdown, and the opening angle of three electro-pneumatic valves (providing feedback for air flow regulation through expander, for flow through the bypass circuit, and for outlet air flow).
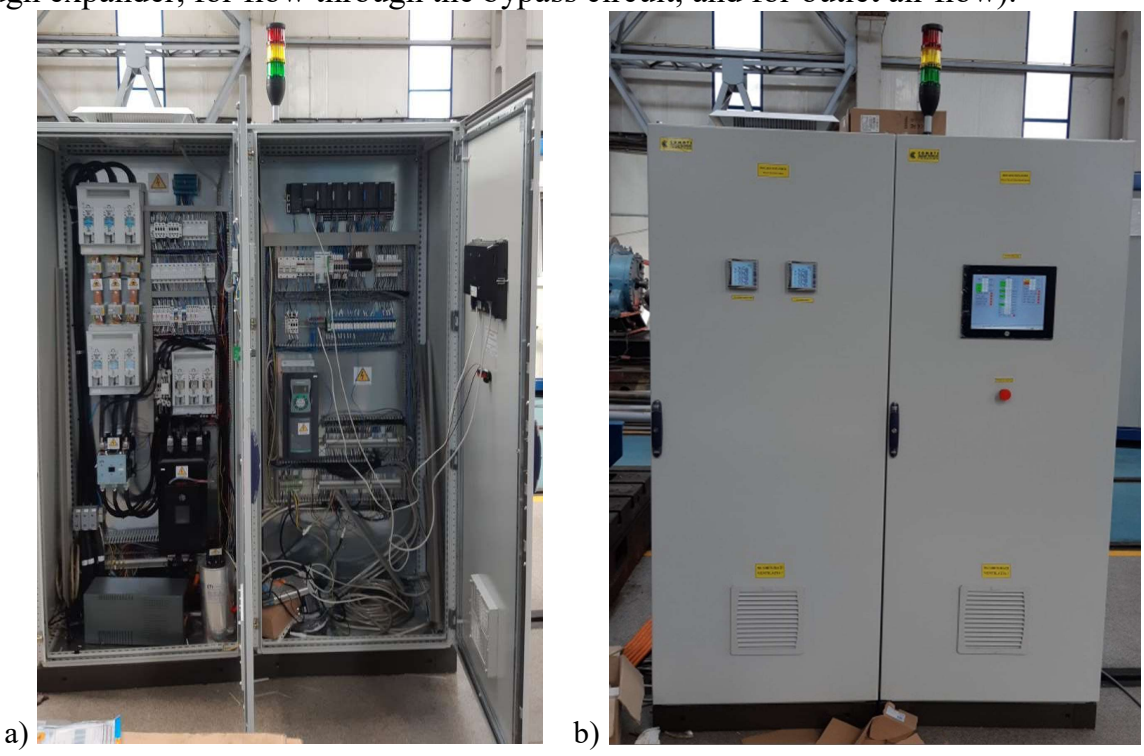

Fig. 6. Automation cabinets assembly: a) fully equipped, with open doors; b) during operation

The asynchronous three-phase machine of the expander is started in motor regime, using a softstarter, until reaching no load speed $(\sim 1470 \mathrm{rpm})$. The compressed air released turns the expander, which spins the shaft of the electric machine above the synchronous speed of $1500 \mathrm{rpm}$, this one entering automatically in generator regime and supplying electrical power into the grid. The speed of the machines is maintained constant, thus being possible to use softstarters instead of variable speed drives, and therefore reducing costs.

An asynchronous generator is an electric induction motor driven at speeds above its synchronous speed. It has a solid armature (squirrel cage), which acts as an electrical short circuit. When power supplied, the machine will start turning like a motor at a speed slightly below the synchronous speed of stator's rotating magnetic field. If the rotor is driven at exactly the synchronous speed $(1500 \mathrm{rpm})$, the magnetic field rotates at the same speed as the rotor, causing no induction phenomena in the rotor, which will not interact with the stator. If the speed is increased above the synchronous speed, the rotor moves faster than the rotating magnetic field of the stator, and the stator induces a current in the rotor. The more mechanical power that is delivered to the rotor, the more power will be transferred as electromagnetic force to the stator, and consequently converted into electricity, which is supplied into the electrical grid.

The choice of using asynchronous induction machines in the detriment of synchronous machines brings significant advantages:

- No additional manoeuvres for coupling to the electrical grid;

- Asynchronous electric machines are able to operate without requiring any human operator intervention, rendering the start-up - loading - connection to electrical grid cycle to be completely automatic;

- High dynamic load capacity;

- High start-up capacity.

However, besides providing a lower efficiency than synchronous machines, the asynchronous generator also has a reactive power component. During operation, a 
continuous, oscillating reactive power exchange occurs between the generator and the electrical grid. For overcoming this disadvantage, a three-phase capacitor has been ensured. The capacitive reactance provides the reactive power component to the electric machine, thus avoiding inducing power fluctuations in the electrical grid.

The apparent power of an asynchronous generator consists of an active power component and a reactive power component and is measured in VA (Volt Ampere). The active power (at shaft) is the actual mechanical power measured in $\mathrm{W}$ (Watts).

\section{Estimated power computations}

This section presents the computations made for the power expected to be produced by the generator. The expander works at a suction pressure $p_{s u c}=20$ bar absolute $(2 \mathrm{MPa})$. At $20^{\circ} \mathrm{C}$ and $60 \%$ relative humidity, the mass air flow rate is $M_{\text {air exp }}=1500 \div 4500 \mathrm{~m}^{3} / \mathrm{h}$ and the volume flow rate is $Q_{\text {air } \text { exp }}=0.487 \div 1.461 \mathrm{~kg} / \mathrm{s}$ [13]. The computations considered the minimum and maximum volume flow rates in $[\mathrm{kg} / \mathrm{s}]$.

The discharge pressure $p_{\text {dis }}$ is 2 bar absolute. The expansion ratio is:

$$
\pi_{\text {exp }}=\frac{p_{\text {suc }}(a b s)}{p_{\text {dis }}(a b s)}=10
$$

The temperature in the storage vessel will increase adiabatically from compressor output temperature, according to [14]. If $t_{\text {comp }}=90^{\circ} \mathrm{C}$ and the initial pressure in the storage vessel $p_{s t, i n}=2$ bar absolute, the compressed air temperature in the storage vessel is calculated, at a maximum final pressure attained of $p_{s t, f i n}=26$ bar absolute:

$$
T_{\text {st,fin }}=\left(t_{\text {comp }}+273.15\right) \cdot \frac{k}{1+(k-1) \cdot \frac{p_{\text {st }, \text { in }}}{p_{\text {st }, \text { fin }}}}=493.23 \mathrm{~K} \Rightarrow t_{s t, f \text { in }}=220.08^{\circ} \mathrm{C}
$$

The nominal operating regime of the system corresponds to the following parameters:

- $p_{\text {suc }}$ - air pressure at the inlet of the expander: 20 bar (abs);

- $p_{\text {dis }}$ - discharge air pressure of the expander: 2 bar (abs);

- $\dot{m}$ - air mass flow rate: $1500 \div 2500 \mathrm{~m}^{3} / \mathrm{h}$, at $20^{\circ} \mathrm{C}$ and $60 \%$ humidity;

- $Q$ - air volume flow rate: $0.487 \div 0.812 \mathrm{~kg} / \mathrm{s}$, at $20^{\circ} \mathrm{C}$ and $60 \%$ humidity;

- $k$-adiabatic exponent: 1.4

- $\eta_{i z}$ - isentropic expander efficiency: 0.7 ;

- $R$ - gas constant: $287 \mathrm{~J} /(\mathrm{kgK})$.

Due to the oil injected screw turbine, the oil will be heated/cooled, which will cause a constant temperature at the compressed air inlet in the turbine. The suction temperature will be maintained constant at maximum temperature supported by the expander of $t_{s u c}=135^{\circ} \mathrm{C}$ ( $T_{\text {suc }}=408.15 \mathrm{~K}$ absolute value).

The temperature difference $\Delta T \cong 85^{\circ} \mathrm{C}$ is used to compensate the storage heat losses, which can oscillate depending on insulation, from 3.5 to $5^{\circ} \mathrm{C} / \mathrm{h}$. The calculations were performed for different storage tank diameters and insulation thicknesses, for an external storage vessel of $150 \mathrm{~m}^{3}$. The specific heat $c_{p}$ at constant pressure is:

$$
c_{p}=k \cdot R /(k-1)=1.010 \mathrm{~kJ} /(\mathrm{kgK})
$$

The power of the expander is calculated using the following relation:

$$
P_{e X}=\dot{m} \cdot \eta_{i z} \cdot c_{p} \cdot T_{\text {suc }} \cdot\left[1-\left(\frac{1}{\pi_{\text {exp }}}\right)^{\frac{k-1}{k}}\right]=73.8 \div 112.9 \mathrm{~kW}
$$


Considering generator efficiency $\eta_{g e n}=0.9$, the estimated power generated will be:

$$
P_{\text {gen }}=P_{\text {exp }} \cdot \eta_{\text {gen }}=66.4 \div 101.6 \mathrm{~kW}
$$

\section{Commissioning tests for expander-generator system}

The functionality of the expander-generator system was tested with the air inlet supply connected to a $250 \mathrm{~kW}$ screw CHP (Compressor of High Pressure) designed by INCDT COMOTI for attaining high pressures up to $40 \mathrm{bar}$. The electric machine of the expander was started up in motor regime, with expander air inlet valve open. The system start-up must be realized only with the inlet valve open because otherwise vacuum is created during expansion, inducing large vibrations in the equipment when vacuum is discharged at the outlet, into a higher external atmospheric pressure.

When the compressed air pressure and flow became sufficient to turn expander's helical screw rotors, the shaft spinning above the synchronous speed determined the generator to produce electrical energy. The power consumption as motor, as well as the power generated and supplied into the grid are displayed by the power analysers. The consumed power values are positive and the generated power is displayed as negative (figure 7).

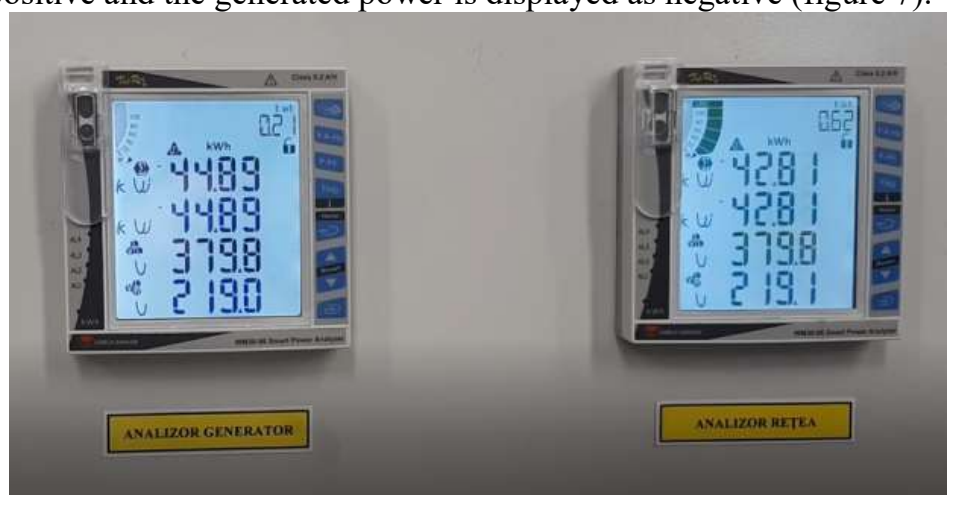

Fig. 7. Power generated (left) and power supplied into grid (right) displayed on the analysers

The power analysers transmit the data to the PLC using Ethernet communication protocol, also displaying the information on the control panel, along with the important operational parameters (figure 8).

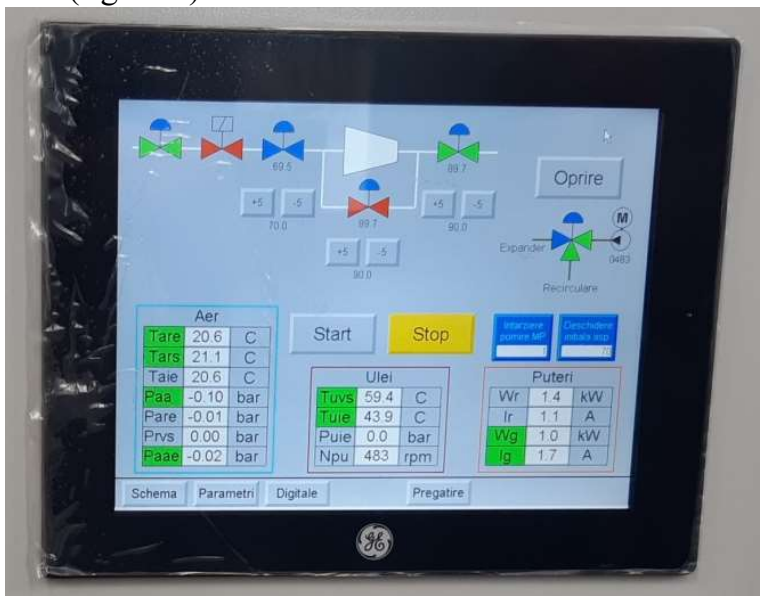

Fig. 8. Control panel displaying technological diagram screen and important parameters 
Data acquisition (DAQ) was performed during commissioning tests. Parameters values were acquired through the program realized in Proficy Machine Edition software, by connecting the computer on which the program was ran to an Ethernet module enabling the communication with the PLC. Relying on the DAQ, the subsequent graph was represented.

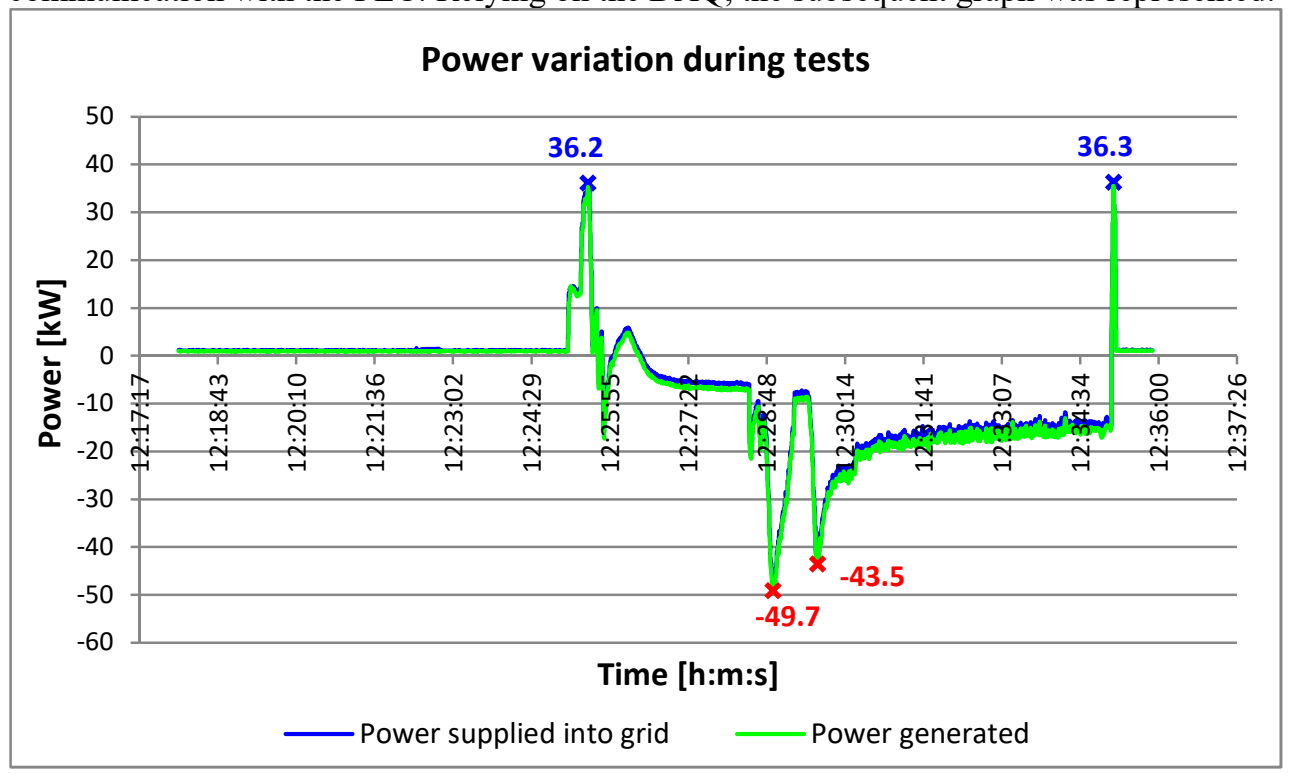

Fig. 9. Power variation chart drawn with acquired data

As it can be observed from the graph above, the power supplied into the grid is slightly lower. The reason is that the $4 \mathrm{~kW}$ motor of the oil pump and the electrical equipment in the automation cabinets also have to be supplied from the generated power.

The CHP provided a pressure of 12-14 bar, air entering the expander at around 4 bar. By increasing the air flow at expander inlet, a maximum generated power of $49.7 \mathrm{~kW}$ was recorded, the power supplied into the grid being of $48.4 \mathrm{~kW}$.

A peak of consumed power of $36.2 \mathrm{~kW}$ from the electric grid occurs at rated speed as motor. Another peak of $36.3 \mathrm{~kW}$ power consumption occurs when stopping the expandergenerator system, due to suddenly cutting off the compressed air supply. In the complete ROCAES application, the compressed air released from the storage vessels is expected to provide a smooth operation stop, as air pressure will decrease gradually in the reservoirs.

\section{Conclusions}

The paper proposes a CAES installation with air storage in vessels. The solution presented is a low scale model, suited for electrical power backup on small areas such as villages. ROCAES system can be used for ensuring a continuous electrical energy distribution when interruptions occur in the power generated by wind turbines or solar panels.

The advantages of ROCAES installation design are:

- high product efficiency due to an almost isothermal expansion - by oil injection;

- high flexibility for variations of gas parameters at the expander suction;

- small scale model, able to be replicated easily;

- eliminating terrain restrictions and constraints regarding special geological structures to provide compressed air storage, such as caverns and salt mines. ROCAES power plant can basically be placed in any area respecting the environmental conditions for which it has been designed. 
The paper presents the concept and design of the first CAES power plant developed in Romania. A maximum generated power of $49.7 \mathrm{~kW}$ was attained during commissioning tests of expander-generator system, with the air inlet connected to a high pressure screw compressor. ROCAES is an ongoing project, only the expander part being completed so far. The overall installation has not yet been functionally tested. The mathematical calculations estimate that the facility will be able to produce up to $100 \mathrm{~kW}$.

The estimated operation time is about 30 minutes, being limited by storage vessels capacity. The power and the operation time are not that high, but are enough to validate the conceptual model with low costs. An underground cavern is currently being searched for increasing the air volume stored and therefore the operation time.

Future research will focus on optimising the oil temperature conditioning circuit by introducing photovoltaic panels for oil heating. Using a system for oil thermal energy storage (TES) has also been discussed. Solutions for reducing pressure drops and losses will also be studied.

The research work presented herein was funded by Competitiveness Operational Program 2014-2020, Priority Axis 1 - Research, Technological Development and Innovation in Support of Economic Competitiveness and Business Development, Action 1.2.3, Partnerships for Knowledge Transfer, contract no. 79 / 08.09.2016, carried out with the support of Romanian Ministry of European Funds.

\section{References}

1. A. Cristescu, C.G. Alionte, Echipamente Termice Clasice și Nucleare ETCN (2008).

2. W.V. Loscutoff, Ener. Stor., 467-471, (Elsevier, 1980).

3. http://www.apexcaes.com/caes.

4. K. Vosburgh, J. of Ener., 2, no. 2, 106-112 (1978).

5. O.K. Mawardi, Energy Storage for Electric Utilities (1981).

6. M. Masoum, E. Fuchs, Power Quality in Power Systems and Electrical Machines, 9611084 (2015).

7. L. Rublack, O. Warweg, P. Bretschneider, S. Freund, M. Bieber, 2016 IEEE PES Innovative Smart Grid Technologies Conference Europe (ISGT-Europe) (2016).

8. S. Donadei, G. Schneider, Storing Energy, 113-133 (2016).

9. J. Wang, K. Lu, L. Ma, J. Wang, M. Dooner, S. Miao, J. Li, D. Wang, Ener. 10, no. 7, (2017).

10. T.M.I. Mahlia, T.J. Saktisahdan, A. Jannifar, M.H. Hasan, H.S.C. Matseelar, Renew. and Sust. Ener. Rev. 33, 532-545 (2014).

11. K. Ding, J. Zhi, Large-Scale Wind Power Grid Integration, 211-232 (2016).

12. https://www.lowtechmagazine.com/2018/05/ditch-the-batteries-off-the-gridcompressed-air-energy-storage.html.

13. N. Toma, V. Petrescu, M. Nițulescu, Huitième édition du COlloque FRancophone en Energie, Environnement, Economie et Thermodynamique, COFRET'16 (2016).

14. V. Radcenko, N. Alexandrescu, E. Ionescu, M. Ionescu, Calculul şi proiectarea elementelor şi schemelor de automatizare (1985). 